Western University Scholarship@Western

1973

\title{
Effective Location Subsidies: An Evaluation of DREE Industrial Incentives
}

Robert S. Woodward

Follow this and additional works at: https://ir.lib.uwo.ca/economicsresrpt

Part of the Economics Commons

Citation of this paper:

Woodward, Robert S.. "Effective Location Subsidies: An Evaluation of DREE Industrial Incentives." Department of Economics Research Reports, 7322. London, ON: Department of Economics, University of Western Ontario (1973). 
RESEARCH REPORT 7322

EFFECTIVE LOCATION SUBSIDIES: AN EVALUATION OF DREE INDUSTRIAL INCENTIVES ${ }^{\dagger}$

Robert S. Woodward

November, 1973 


\section{Introduction}

Although the Canadian federal government has spent hundreds of millions of dollars to increase manufacturing employment in economically depressed regions such as the Atlantic Provinces, the relative employment impacts of alternative location subsidies have not been correctly evaluated. In the context of a Weberian neoclassical model which allows for input substitution and output expansion, this paper examines the size of four location subsidies which would make a firm just indifferent between a low and a high cost site. The incentives considered include subsidies for each of two inputs, for production and for location at the high cost site. The relative employment impacts are evaluated: 1) for each firm and 2) per dollar of government incentive expenditure.

While the relative costs of alternative regional subsidies have not been accurately specified, the issue has received some attention in the literature. In a recent discussion paper from the Economic Council of Canada, Emerson $(1973,14)$ incorrectly argues that an output subsidy will always cost less than an input subsidy. Emerson's error occurs because he fails to consider the output effect of the production subsidy. His results are further confused by the incorrect specification of the iso-outlay curve. And his conclusions are not directly applicable to Canadian regional problems because he does not relate his analysis to the current policies and objectives of the Department of Regional Economic Expansion (DREE).

In an article in the Canadian Journal of Economics, this author (1974) documents the capital bias of DREE incentives and indicates that the Department's subsidies are inconsistent with their employment objectives. However, the extent of the inconsistency is not proved in a rigorously defined mode1. This paper supplements that article by demonstrating that, with a few weak assumptions, 
capital biased subsidies are the least consistent with regional employment objectives.

In a model of a single region, Borts and Stein (1964) argue that a labour subsidy is the most efficient regional growth incentive. In a similar context, Bhagwati and Srinivasan (1969) have argued that employment subsidies are an optimal means of affecting the noneconomic objective of reducing a particular region's unemployment. In a manner characteristic of much of the international trade literature, both models assume inelastic labour supplies and do not recognize that factor price differentials may continue because of transport costs or market imperfections. In contrast, this paper examines the location decision of a relatively small firm which faces fixed, but different, factor prices in two regions.

In the following section, this paper proceeds by presenting a twopoint two-factor Weberian location model. In section III, the effects and costs of a site subsidy, a production subsidy and two input subsidies are determined where output is held constant. In section IV, the effects and costs of the four subsidies are evaluated where output is optimized. The site subsidy is shown to be the cheapest way to affect a firm's location. In section $V$, the current DREE incentives are shown to have a smaller employment impact for each firm and to cost the government more per job than alternative programs.

II. A Weberian Model of Location and Production

This section develops a model in which a profit maximizing firm is free to locate anywhere along a line and manufactures its output using two substitutable factors. The firm's production and location are determined graphically 1) by the tangency between the iso-outlay line and 
the production isoquant and 2 ) by maximizing the difference between the total cost and total revenue curves.

Let Ontario, 0 , and Nova Scotia, $N$, be considered two points connected by a straight line. The firm is assumed to be able to locate in Ontario, Nova Scotia or any point along the connecting line ON (Figure 1). The firm is assumed to face 1) a perfectly elastic supply of capital, $K$, at a lower price in Ontario than in Nova Scotia and 2) a perfectly elastic supply of labour, L, at a lower price in Nova Scotia than in Ontario. The differences in factor prices may be attributed to transport costs and/or regional factors. The only necessary restrictive assumption is that the factor prices may not increase at an increasing rate with distance. This assumption is equivalent to non-increasing transportation costs.

\section{Figure 1}

Set of Feasible Locations

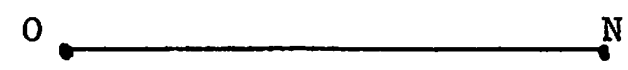

The firm is assumed to produce its output, $Q$, according to the homothetic production function

1)

$$
\mathrm{Q}=\mathrm{F}(\mathrm{K}, \mathrm{L}) \text { 。 }
$$

While the market for $Q$ may be considered to be in the United States, in 
Canada, in Ontario or in Nova Scotia, the firm is assumed to face a perfectly elastic demand at the same price regardless of its location. Such would be the case if the firm were small enough to be a price taker in export markets and if the output transport costs were either zero or constant for all possible locations.

Since the firm must pay a higher price for capital in Nova Scotia, it can buy less capital for the same outlay than it could if it would locate in Ontario. Similarily, since the firm must pay a higher price for labour in Ontario, it can buy less labour for the same outlay than it could if it would locate in Nova Scotia. Thus, it is possible to draw isocost lines, such as $\mathrm{K}_{1} \mathrm{~L}_{1}^{0}$ and $\mathrm{K}_{1} \mathrm{~N}_{1} \mathrm{~N}_{1}$ (Figure 2), which represent equal outlays for a firm's location on Ontario and Nova Scotia respectively. Since the factor prices were assumed to increase at a non-increasing rate with distance, the isocosts for points $\mathrm{O}$ and $\mathrm{N}$ dominate the isocosts for a11 locations between 0 and $N{ }^{1}$ Thus, the iso-outlay curves take the shape of $\mathrm{K}_{1}^{0} \mathrm{M}_{1} \mathrm{~L}_{1}^{\mathrm{N}}$ and $\mathrm{K}_{2}^{\mathrm{O}} \mathrm{M}_{2} \mathrm{~L}_{2}^{\mathrm{N}}$ (Figure 2).

Where the production function is assumed to be relatively capital intensive, a production isoquant such as $Q=Q_{1}$ will be tangent to the isooutlay $\mathrm{K}_{1}^{\mathrm{O}} \mathrm{M}_{1} \mathrm{~L}_{1}^{\mathrm{N}}$ as a point such as $\mathrm{B}$ (Figure 2). In addition to indicating the quantities of $K$ and $L$ which the firm will use to produce $Q_{1}$, the tangency $B$ indicates that the firm will locate in Ontario. Since the production function is assumed to be homothetic, the firm will locate in Ontario regardless of its scale and produce its output with the factor proportion indicated by the straight expansion path $A B C$ (Figure 2). If for some reason, the firm were forced to locate in Nova Scotia, the firm's expansion path would be indicated by the ray ADE (Figure 2). 


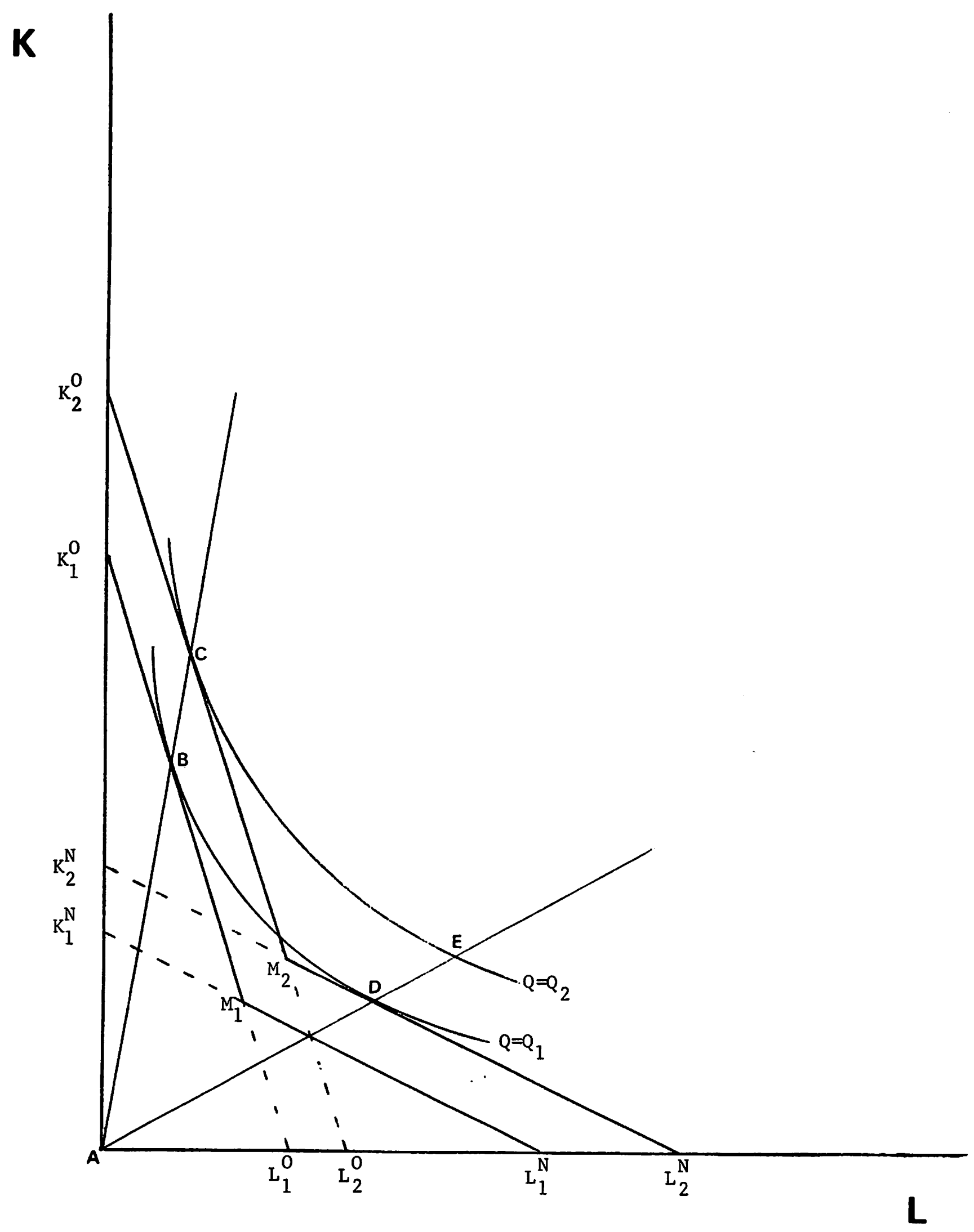

Figure 2 
For each of these expansion paths, it is possible to derive a total cost curve. Since the production function is assumed to realize increasing, and then decreasing returns to scale, the total cost curve for both expansion paths will demonstrate decreasing, and then increasing marginal costs.

Because the exact position of these total cost curves will be important for the conclusions about least cost incentives, two propositions about the relative total cost curves are presented. First, homotheticity is a sufficient condition to prove that if total costs in Ontario and Nova Scotia are equal for some output, they will be equal for all levels of output. The corollary--if total costs in Nova Scotia are greater for some level of output, they will be greater for all levels of output--is stated without proof. Second, homotheticity is also sufficient to prove that when the firm earns no profit, the optimun level of output in both locations is the same.

The proof of the first proposition follows from the lemma that if a production function is homothetic, the production elasticity will be a function of output and not factor proportions. Any homothetic production function $Q=F(K, L)$ may be written:

$$
Q=G[f(K, L)]=G[q]
$$

where $G$ is a monotonic transformation, and

$$
q=f(K, L)
$$

is a linearly homogeneous production function. The production elasticity $\epsilon$ may be shown to equal ${ }^{2}$

3)

$$
\epsilon=\left[F_{K} K+F_{L} L\right] / Q \text {. }
$$

Where $F$ is homothetic, 
Since $G$ is a monotonic transform of the output $q$, $q$ and $G^{\prime}$ may be written as functions of $Q$. Therefore $\epsilon$ is a function of $Q$ and not the factor proportions.

It remains to prove that where $\epsilon$ is a function of output and the firm is just indifferent between two locations at some output, it will be just indifferent for all outputs. The firm will just be indifferent between locationsif its production isoquant is tangent to both the isocost in Ontario and the isocost in Nova Scotia (Figure 3). A given percentage increase in the firm's outlay will allow equal percentage increases in the purchases of inputs at 0 and $N$. And since the initial output was the same at the two sites, the equal percentage increase in inputs will cause an increased output of exactly the same amount at both sites. Thus, if one isoquant was tangent to the equal-outlay isocosts in Ontario and Nova Scotia, isoquants for all outputs will be tangent to the equal-outlay isocosts at the two sites (Figure 3). In this case, costs at both sites will be equal for each output and the two total cost curves will be identical. Two corollaries follow from the first proposition. First, if one production isoquant is tangent to a higher isocost line at $\mathrm{N}$ than at 0 , then total costs will be higher at $N$ for all levels of output. Second, where costs are higher at $\mathrm{N}$ and where marginal costs are increasing at 0 , marginal costs at $\mathrm{N}$ are greater than at 0 . The proof of both corollaries follows from a consideration of Figures 2 and 3, and are sufficiently straightforward to not require explanation. 


$$
-8-
$$

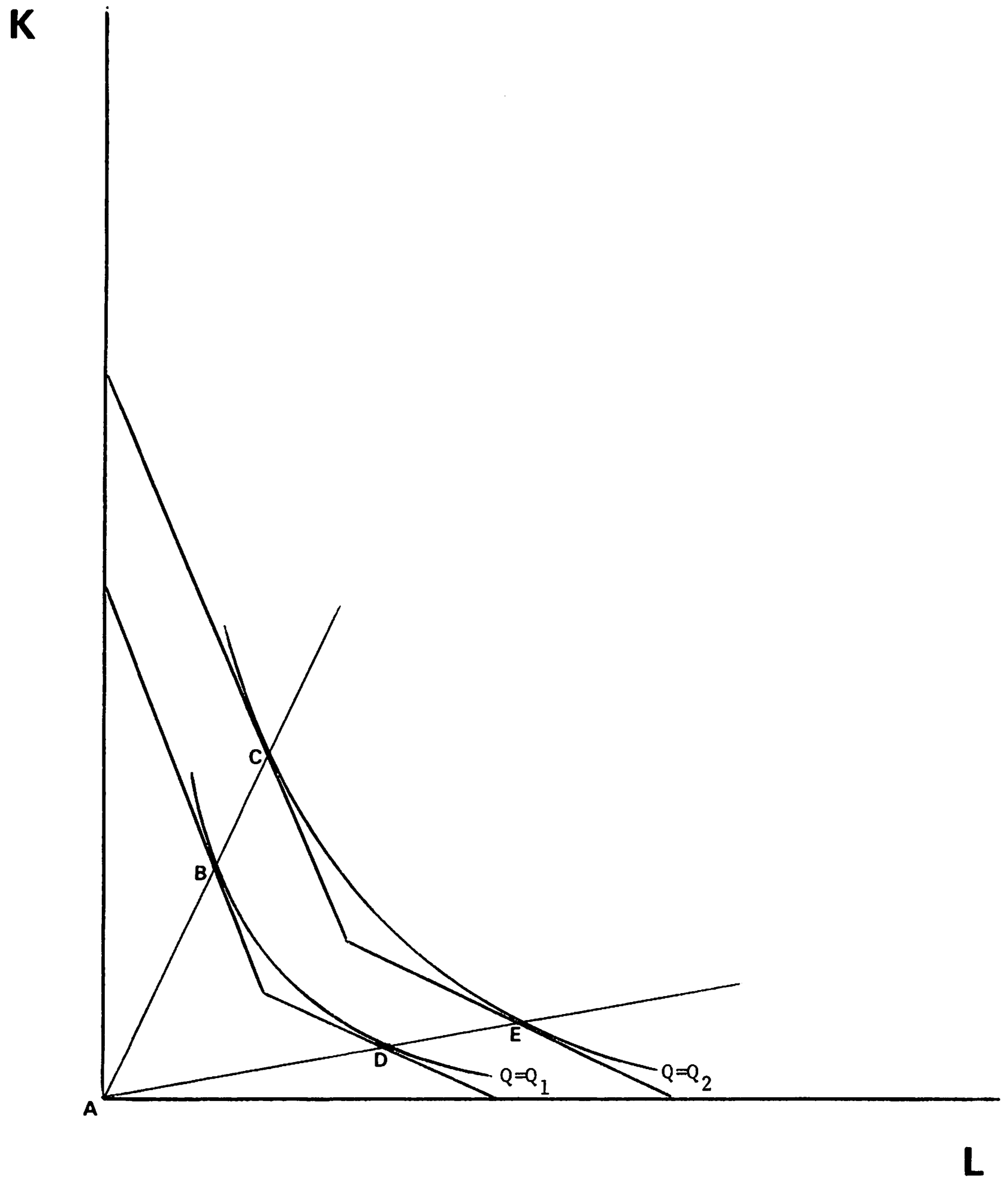

Figure

3 
The second proposition gives an additional comparison between the total cost curve at $\mathrm{N}, \mathrm{TC}^{\mathrm{N}}$, and the total cost curve at $0, \mathrm{TC}^{\mathrm{O}}$ (Figure 4 ). If the output price is such that the total revenue curve in Ontario, $\mathrm{TR}^{0}$, happens to be just tangent to $\mathrm{TC}^{0}$, and the total revenue curve in Nova Scotia, $T R^{N}$, happens to be just tangent to $T C^{N}$, the firm will operate with zero profit at an output determined by each tangency. At each tangency and for both locations, the average cost just equals the marginal cost. Thus the cost elasticities, defined as equal to the marginal costs over the average costs, equal one. Moreover, any cost elasticity is equal to the inverse of the production elasticity. Since the production elasticity has been shown to be a function of output, and since the production elasticity takes the value one at only one output, the zero profit output, $Q_{1}$, is equal for both locations (Figure 4 ).

III. Subsidies in Input Space

This section compares the size of the alternative subsidies which would make the firm just indifferent between the two sites where output is held constant. The firm is assumed to have a relatively capital intensive production function so that in the absence of subsidies its optimum location site is in Ontario. The output effects of the subsidies are considered in the following section.

Throughout this and the remaining sections, it is convenient to measure the firm's costs and the value of government subsidies in units of labour. The firm's cost is indicated by the intersection of its initial isocost with the labour axis. The value of the government subsidy is indicated by the distance along the labour axis between the initial isocost and the tangency of the isoquant with the subsidized isocost. The dollar cost to the firm and the dollar value 
$-10-$

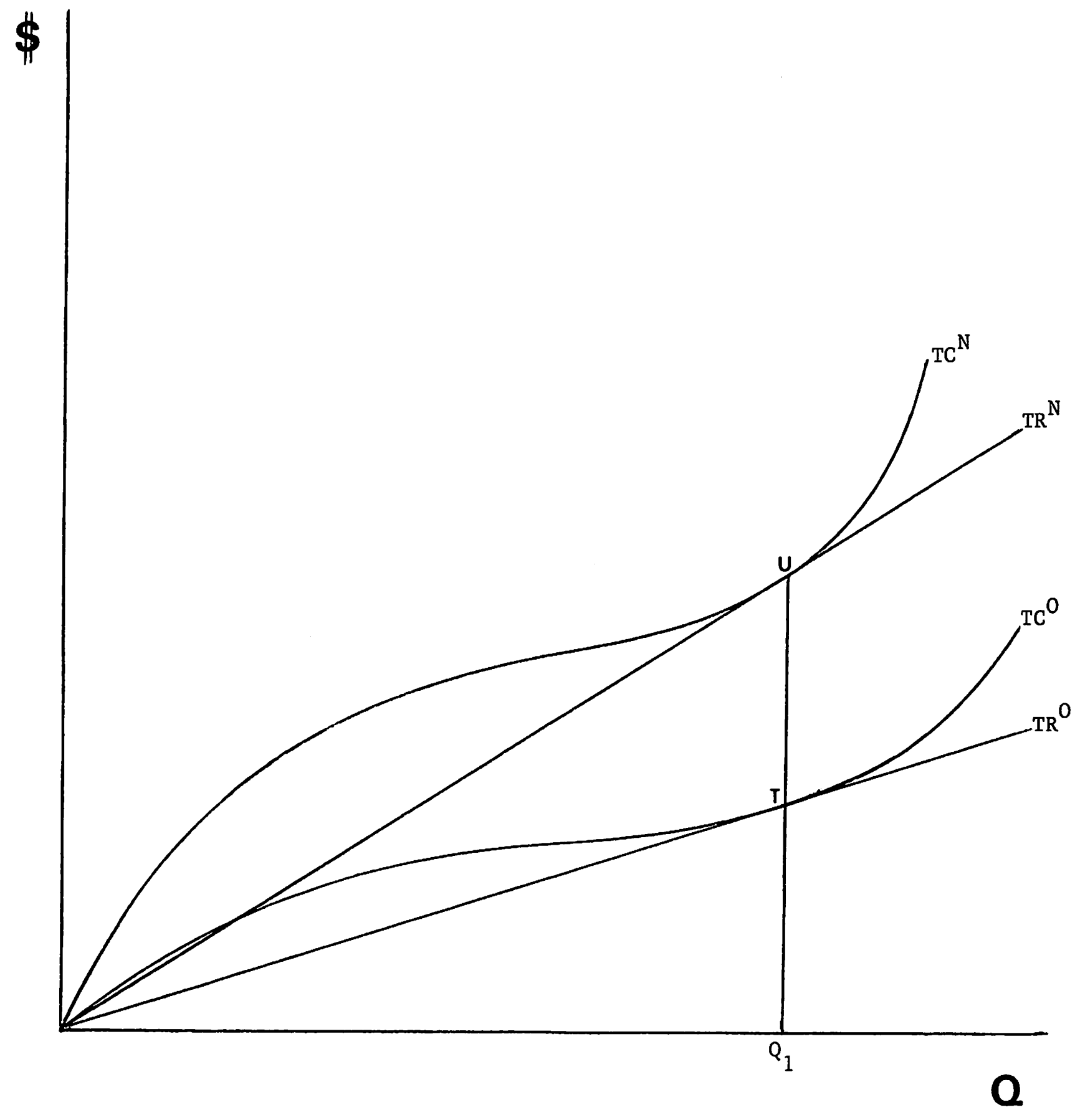

Figure 4 
of the subsidy could be calculated by multiplying the respective labour units times labour's initial price in the region receiving the subsidy.

Consider the initial equilibrium indicated by the tangency of the production isoquant $Q=Q_{1}$ and the iso-outlay curve $K^{0} M_{1}^{N}$ at the point $F$ (Figure 5). Any subsidy which shifts the isocost at $N, K_{1}^{N_{1}} L_{1}^{N}$, so that it is tangent to the isoquant $Q=Q_{1}$ will make the firm indifferent between the two locations. The following paragraphs consider the effect of two input subsidies, an output subsidy and a site subsidy.

Subsidies proportional to input quantities, subsidies for the prices of inputs, and subsidies for the transportation costs of inputs all make it possible to buy more of the subsidized input for a given outlay. Since these subsidies all have the same qualitative and quantitative effect, they are all considered as an input subsidy and no distinction is made between the three forms of payment.

A capital subsidy which would shift the initial Nova Scotia isocost curve so that it is just tangent to the isoquant $Q=Q_{1}$ is indicated by the line $\mathrm{K}_{3} \mathrm{~L}_{1}^{\mathrm{N}}$ (Figure 5). For this subsidy, the firm will use the quantities of capital and labour indicated by the tangency at $G$, and will receive a subsidy whose value is indicated by JG (Figure 5). At G the total costs for producing $Q_{1}$ equals the outlay by firm indicated by $L_{1}^{N}$ plus the subsidy JG.

A labour subsidy which would shift the initial isocost curve in Nova Scotia so that it is just tangent to the isoquant $Q=Q_{1}$ is indicated by the line $\mathrm{K}_{1}^{\mathrm{N}_{3}} \mathrm{~N}$ (Figure 5). For this subsidy, the firm will use the quantities of capital and labour indicated by the tangency at I, and will receive a subsidy whose value is indicated by SI (Figure 5). At I, the total cost of producing $Q_{1}$ equals the outlay by the firm as indicated by the intercept $\mathrm{L}_{1}^{\mathrm{N}}$ plus the subsidy SI. 


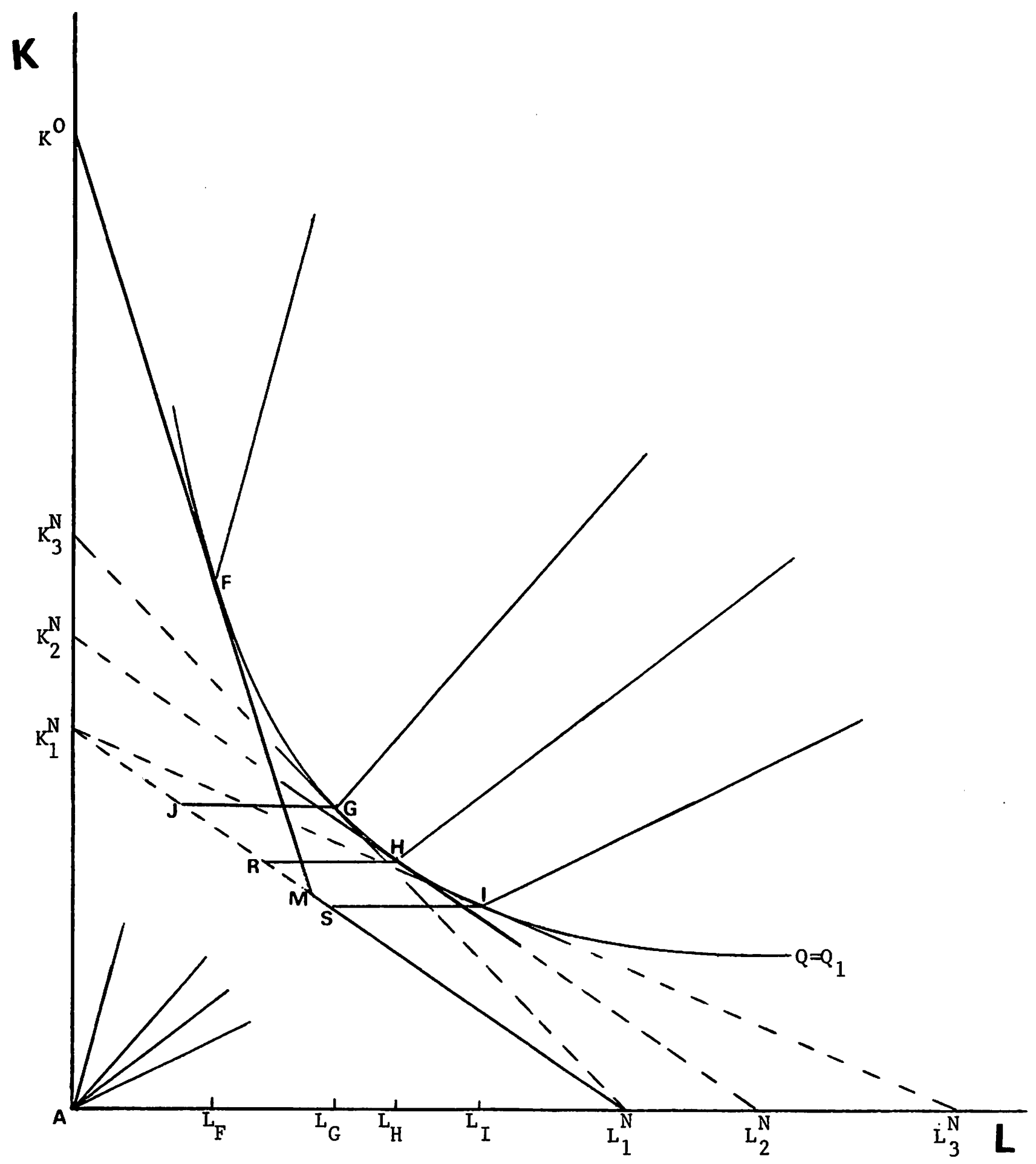

Figure 5 
In input space, site subsidies and production subsidies are indistinguishable. A site or a production subsidy which would make the firm just indifferent between the two locations is indicated by the isocost $\mathrm{K}_{2}^{N_{1}} \mathrm{~N}_{2}^{\mathrm{N}}$ (Figure 5). For this subsidy, the firm will use the quantities of capital and labour indicated by the tangency at $\mathrm{H}$, and will receive a subsidy whose value is indicated by RH. Since where output is constant, subsidizing an input causes the firm to change its location and to increase its use of the subsidized input, a site or a production subsidy costs the government less than either input subsidy. In the graphical analysis, $\mathrm{RH}$ is less than either JG or SI.

IV. The Subsidies in Output and Total Cost Space

This section compares the magnitude of the alternative subsidies where output is optimized. Although the site and production subsidies were equivalent where output was held constant, they cannot be equal where the firm can adjust output to maximize profits. The firm is assumed to be indifferent between the two locations if the subsidies are just sufficient to allow the firm equal profits in both provinces. Most of the analysis in this section is based on the assumption that firms earn zero profit.

In order to compare the size of the subsidies, it is convenient to assume a correspondence between the curves in input space and those in output space. First, suppose that $\mathrm{TC}^{0}$ (Figure 6) represent the total cost curve in Ontario which is derived from the cost and output relations along the expansion path $\mathrm{AF}$ (Figure 5). Second, assume that $\mathrm{TC}_{1}^{\mathrm{N}}$ (Figure 6) represents the costs of producing each level of output along the expansion 
$-14-$

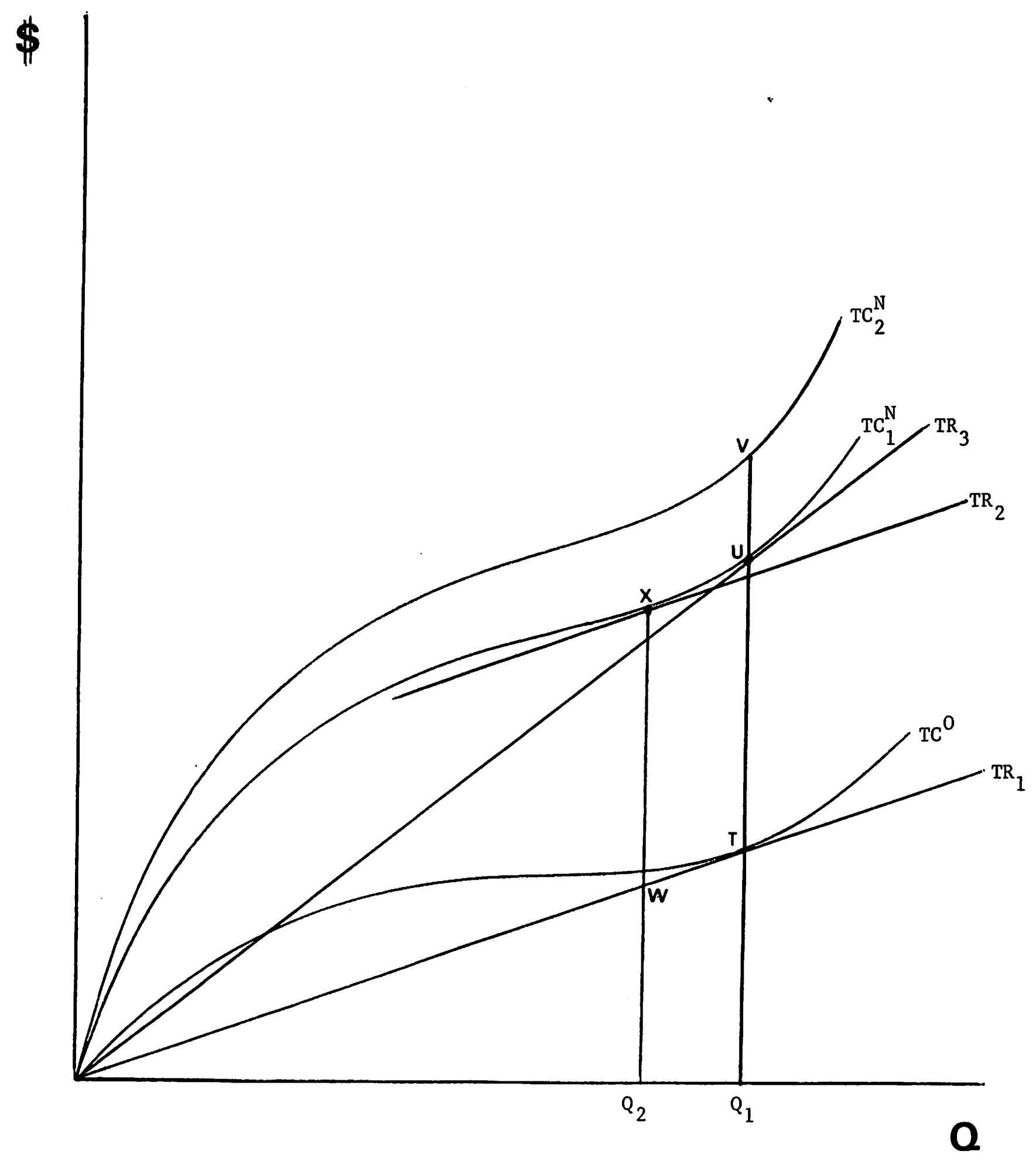

Figure 6 
path $\mathrm{AH}$ (Figure 5). Third, 1et $\mathrm{TC}_{2}^{\mathrm{N}}$ (Figure 6) be the total costs of each output along either expansion path AI or AG (Figure 5). Since the cost of producing each output level is greater along $\mathrm{AI}$ or $\mathrm{AG}$ than along $\mathrm{AH}, \mathrm{TC}_{2}^{\mathrm{N}}$ is everywhere above $\mathrm{TC}_{1}^{\mathrm{N}}$. Finally, suppose that the initial total revenue line, $\mathrm{TR}_{1}$, happened to be tangent to $\mathrm{TC}^{0}$ at $\mathrm{T}$ (Figure 6 ). In the absence of any subsidy, the firm would locate in Ontario and produce an output $Q_{1}$ 。

If the firm were to receive a site subsidy, total revenue would be increased by the amount of the subsidy, but marginal revenue would remain constant. The site subsidy which would make a firm just indifferent between the two sites is illustrated by the total revenue curve $T R_{2}$ which is just tangent to $\mathrm{TC}_{1}^{\mathrm{N}}$ at $\mathrm{X}$. At that tangency, the firm would produce an output $\mathrm{Q}_{2}$ and receive a subsidy equal to $\mathrm{WX}$.

If the firm receives a production subsidy, the firm effectively receives a higher price for each unit of output. Thus,

the slope of the total revenue curve increases. A subsidy just sufficient to make the firm indifferent between an Ontario and a Nova Scotia is illustrated by $\mathrm{TR}_{3}$ which is just tangent to $\mathrm{TC}_{1}^{\mathrm{N}}$ at $\mathrm{U}$ (Figure 6). Since the production function was assumed to be homothetic, the output indicated by the tangency $U$ is equal to the output indicated by the tangency $T^{3}$ Thus, the firm will produce an output $Q_{1}$ and receive a subsidy UT. Since at each $Q$ marginal costs along $\mathrm{TC}_{1}^{\mathrm{N}}$ are greater than along $\mathrm{TC}^{0}$, and since $\mathrm{Q}_{1}>\mathrm{Q}_{2}$, TU must be greater than $W \mathrm{X}$.

If the firm receives an input subsidy, then it will produce along the expansion path $\mathrm{AG}$ or $\mathrm{AI}$ (Figure 5) and operate with costs indicated by $\mathrm{TC}_{2}^{\mathrm{N}}$. As indicated in a previous section, an input subsidy on either labour or capital would reduce the total cost curve at each level of production. An input subsidy which would make the firm just indifferent between Nova 
Scotia and Ontario would be indicated by the shift from $\mathrm{TC}_{2}^{\mathrm{N}}$ to $\mathrm{TC}^{\mathrm{O}}$. With such an input subsidy, the firm would be indifferent between locating in Ontario and producing $\mathrm{Q}_{1}$ at a cost indicated by $\mathrm{T}$, or locating in Nova Scotia and producing $Q_{1}$ by paying an amount indicated by $T$ and covering the total costs of production by receiving a subsidy TV.

Since the output for the production subsidy and the input subsidy happen to be equal where the firm with a homothetic production function earns zero profits, the input subsidy is always greater than the production subsidy. However, if the initlal product price were such that the firm carns positive profits in Ontario, it could only be indifferent between locations if it would be allowed to earn equal profits in Nova Scotia. Therefore, it is possible that the output effect of the production subsidy could be large enough so that the production subsidy could be greater than the input subsidy even though the input subsidy is always more expensive than the output subsidy at each level of output. Emerson (1973) missed this possible output effect in his Economic Council discussion paper.

V. Implications for DREE Policies

Using this simple Weberian Model, it is possible to evaluate the relative effectiveness of the industrial incentives of the Department of Regional Economic Expansion available under the Regional Development Incentives Act (RDIA). Roughly, the purpose of the RDIA subsidies is to increase employment in certain depressed Canadian regions such as Nova Scotia. In the context of this model, it is possible to ask 1) which of the subsidies would have the greatest employment impact per firm and 2) which subsidy would have the greatest employment impact per dollar of government subsidy. 
Where output is held constant, the employment impacts of the various subsidies are readily apparent. At $Q=Q_{1}$, the firm would have located in Ontario and used $\mathrm{L}_{\mathrm{F}}$ labour as indicated by the tangency $\mathrm{F}$ (Figure 5). For the capital subsidy indicated by GJ, the production or site subsidy indicated by $H R$, or the labour subsidy indicated by IS, the firm would be indifferent to $1 \propto$ ating in Nova Scotia and using $\mathrm{L}_{G}, I_{H}$, and $\mathrm{L}_{I}$ labour respectively. Clearly, employment will be greatest for the labour subsidy, less for the production or site subsidy, and least for the capital subsidy.

Where output is optimized, and profits in the two sites are assumed zero, the optimal output for the production and input subsidies are equal. Thus, labour subsidy increases employment more than the production subsidy, which increases employment more than the capital subsidy. While it is additionally clear that the production subsidy will increase employment more than the site subsidy, comparisons between the site subsidy and the capital subsidy are not possible without exact knowledge of the relative difference between $\left(\mathrm{L}_{H}-\mathrm{I}_{\mathrm{G}}\right) / \mathrm{L}_{\mathrm{H}}$ and $\left(\mathrm{Q}_{1}-\mathrm{Q}_{2}\right) / \mathrm{Q}_{1}$.

It is convenient to use the production subsidy as a point of comparison in the analysis of the government cost per new job, or alternatively, the number of jobs per dollar of government expenditure. Relative to the production subsidy, the site subsidy costs less and causes less employment, while the labour subsidy costs more and causes more employment. Therefore without quantitative information about the production function and factor prices, it is impossible to compare the government cost per new job for these three subsidies. 
Nevertheless, where profits are assumed to be zero, it is possible to compare the extra cost of the labour incentive with the extra employment attributable to the labour incentive. The extra cost of the labour incentive is equal to the difference between HR and IS (Figure 5). As 1ong as the elasticity of substitution is greater than zero, that difference will be less than the extra employment attributable to the labour incentive or $L_{I}-L_{H}$. Thus, while conclusions about the relative costs per new employee of the labour and the production incentive are not possible, the extra cost of the labour subsidy will always be less than the value of the extra employment attributable to the labour incentive.

While conclusions are not possible for the comparisons between costs per new employee for the labour, production and site subsidies, the government payment per new job attributable to the capital subsidy must be greater than the payment per job for production subsidy. This occurs since the number of jobs attributable to the capital subsidy is less, and the subsidy cost is greater than for the production incentive.

In summary, the employment subsidy will have the greatest impact on each firm's employment in Nova Scotia followed by the production subsidy and then the capital or site subsidies. While many comparisons about the relative subsldy Impacts per government dollar are not possible, two strong statements can be made. First, the capital incentive is clearly inferior to the production incentive. Second, when compared to the effect and cost of the production incentive, the value of the extra employment attributable to the labour subsidy is greater than its extra cost. 
In light of the relative advantage of the employment subsidy (and disadvantages of the capital subsidy) in achieving employment objectives, the current practices of the Department of Regional Economic Expansion must be judged inconsistent with their employment goals. DREE seeks to expand employment in regions such as Nova Scotia by offering up to $35 \%$ of a firm's plant, machinery and equipment and up to $\$ 7,000$ per new job (Table 1 ). In an article in the Canadian Journal of Economics, 4 most DREE offers are shown to lower the costs of a firm's capital more than its labour. Thus, firms reacting to DREE offers will expand along a ray from A through some point between $G$ and $H$ (Figure 5). As a result, employment will be affected less than would be possible with a production or labour subsidy and the government will spend more per job than it would have done with a production subsidy. 
Table 1

Maximum DREE Incentives

Location

\section{Region A}

(Atlantic Provinces)

\section{Region B \\ (Standard Designated Regions)}

\section{Region C \\ (Special Designated \\ Region - southwestern \\ Quebec and southeastern \\ Ontario)}

Type of Project

\begin{tabular}{c}
$\begin{array}{c}\text { Modernization } \\
\text { or }\end{array}$ \\
Expansion \\
\hline
\end{tabular}

$30 \%$ of eligible capital costs

$20 \%$ of eligible capital costs

$10 \%$ of eligible capital costs

\section{New Plant or New Product \\ Expansion}

$35 \%$ of eligible capital cost plus $\$ 7,000$ per eligible direct job created

$25 \%$ of eligible capital cost plus $\$ 5,000$ per eligible direct job created

$10 \%$ of eligible capital cost plus $\$ 2,000$ per eligible direct job created

Source: "Assessment of the Regional Development Incentives Program," DREE, 4/73, p. 6 . 


\section{FOOTNOTES}

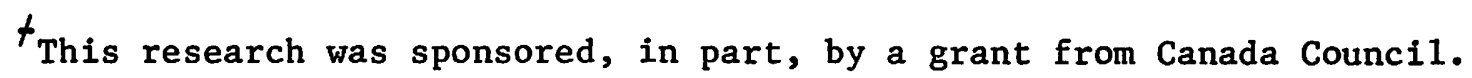
The author wishes to thank Dave Scheffman, Tom Courchene and Mark Frankena for their helpful comments. Remaining errors are the author's responsibility.

Toodward (1973)

${ }^{2}$ Intriligator (1971)

${ }^{3}$ see p. 9

${ }^{4}$ Woodward (1974)

\section{REFERENCES}

Bhagwati, J. and T. Srinivasan. "Optimal Intervention to Achieve Non-Economic Objectives." Review of Economic Studies 36 (Jan. 1969), 27-38.

Borts, G. and J. Stein. Economic Growth in a Free Market (New York, 1964). Canada, Department of Regional Economic Expansion. "Assessment of the Regional Development Incentive Program." One of a series of Staff Papers prepared by the Federal Department of Regional Economic Expansion, April, 1973. Emerson, D. "Location Subsidies, Spatial Friction and the Open Economy." Discussion Paper No. 2, Economic Council of Canada, July, 1973. Intriligator, M. Mathematical Optimization and Economic Theory. (Englewood C1iffs, 1971).

Woodward, R. "The Iso-Outlay Function and Variable Transport Costs。" forthcoming in Journal of Regional Science 8 (Dec. 1973).

Woodward, R. "The Capital Bias of DREE Incentives." forthcoming in The Canadian Journal of Economics 7 (1974): 